CLINICAL AND EXPERIMENTAL VACCINE RESEARCH

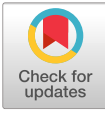

Clin Exp Vaccine Res 2019;8:136-139 https://doi.org/10.7774/cevr.2019.8.2.136 pISSN 2287-3651 • elSSN 2287-366X

Byoung-Shik Shim', Kee-Jong Hong', Puna Maya Maharjan', Sunghwa Choe ${ }^{1,2}$

${ }^{1}$ G+FLAS Life Sciences, Seoul; ${ }^{2}$ School of Biological Sciences, College of Natural Sciences, Seoul National University, Seoul, Korea

Received: July 2, 2019

Revised: July 18, 2019

Accepted: July 28, 2019

Corresponding author: Sunghwa Choe, PhD

School of Biological Sciences, College of Natural Sciences, Seoul National University, 1 Gwanak-ro, Gwanak-gu, Seoul 08826, Korea

Tel: +82-2-872-6691, Fax: +82-2-872-4712

E-mail:Shchoe@snu.ac.kr

No potential conflict of interest relevant to this article was reported.

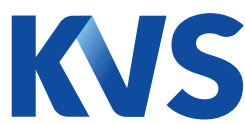

$K O R E A N$

VACCINE

SOC I E T Y

(c) Korean Vaccine Society.

This is an Open Access article distributed under the terms of the Creative Commons Attribution Non-Commercial License (http://creativecommons.org/licenses/ by-nc/4.0) which permits unrestricted non-commercial use, distribution, and reproduction in any medium, provided the original work is properly cited.

\section{Plant factory: new resource for the productivity and diversity of human and veterinary vaccines}

Vaccination is one of the most successful strategies to prevent diseases caused by pathogens. Although various expression systems including Escherichia coli, yeast, insect, and mammalian cells are currently used for producing many of vaccines, these conventional platforms have the limitation of post-translational modification, high cost, and expensive scalability. In this respect, the plant-based expression system has been considered as an attractive platform to produce recombinant vaccines due to fast, cost-effective and scalable production as well as safety. This review discusses the development of plant-derived vaccines and the current stage of plant-based expression system.

Keywords: Transgenic plants, Vaccines, Pharmaceuticals, Antibodies

As a main resource of food and various nutrients for the most living organisms including human and animals, plants are cultured and manufactured for long history. In addition to the contribution as food materials, plants are currently raised as novel resources to produce biopharmaceuticals in forms of enzyme, growth factor, peptide or antibody drugs with highly better productivity and wider diversity. While the traditional agriculture techniques, combined with techniques for developing transgenic plants, were used to supply these biopharmaceutical materials, some advanced plant scientists already tried and advanced to develop plant factory: an integrated system using indoor horticulture technology which can be managed with automatic regulation of environmental parameters, and controlled supplement of nutrition and energy resources. Plant factory system, with its enhanced productivity and strengthened antigenicity, could be utilized for manufacturing recombinant subunit vaccines, peptides as antigens and other various formulation such as virus like particles [1].

Since the functional monoclonal antibody was produced in tobacco [2], currently hundreds of recombinant proteins have been produced from various plants such as tobacco, rice, maize, potato, alfalfa, lettuce, tomato, carrot, and soybean [3]. Among those, bovine trypsin derived from maize has been commercialized since 2002 [4]. Glucocerebrosidase produced in carrot cell culture as the treatment of Gaucher's disease has been first approved for human use by United States Food and Drug Administration [3]. In addition, anti-Ebola antibody (known as ZMapp) produced in tobacco was used for human during 2014 West Africa Ebola virus outbreak [5]. Plant factory for 
Table 1. Plant-derived human vaccines under clinical trails

\begin{tabular}{lllcc}
\hline Pathogen & \multicolumn{1}{c}{ Antigen } & \multicolumn{1}{c}{ Plant } & Clinical trial & Reference \\
\hline Influenza H5N1 & Hemagglutinin & Nicotiana benthamiana & Phase I/II & {$[6,7]$} \\
Influenza H1N1 & Hemagglutinin & Nicotiana benthamiana & Phase I & {$[8]$} \\
Norovirus & Capsid protein & Potato and tobacco & Phase I & {$[9]$} \\
Hepatitis B virus & Surface protein & Lettuce & Phase I & {$[10]$} \\
Hepatitis B virus & Surface protein & Tobacco & Phase I & {$[11]$} \\
Rabies virus & Glycoprotein and nucleoprotein & Spinach & Phase I & {$[12]$} \\
\hline
\end{tabular}

vaccine production is basically same other nutrition or biopharmaceutical production, and also mainly use horticulture system within integrated shielding places such as greenhouses. Although plant-based human vaccines are not approved yet, several vaccine candidates against pathogens such as influenza, norovirus, hepatitis B virus, or rabies virus have been successfully produced in various transgenic plants and tested for their safety and efficacy under clinical trials (Table 1) [612]. For veterinary vaccine, Newcastle disease vaccine derived from tobacco cells was first approved for poultry use by United States Department of Agriculture [13]. In addition, many of recombinant viral proteins from plant system as human or veterinary vaccines have been tested for their immunogenicity against various viruses including human immunodeficiency virus, Ebola, rotavirus, Japanese encephalitis, foot-and-mouth disease virus, and bovine viral diarrhea virus $[3,14]$.

Host plants for vaccine production can be grown massively in plant factory system than in conventional soil-based practice. Plant factory system uses artificial environment controlling $\mathrm{CO}_{2}$ concentration, light quality and quantity, temperature, humidity, and most importantly defined hydroponics media, which secures reproductive and cleaner conditions. Plant factory can supply more benefits to develop and produce vaccines as compared to conventional expression systems. For instance, in the case of pandemic outbreak of influenza, the fast production and scalability of plant factory could be attractive. While egg-based vaccine production takes at least 6 months, Medicago Inc. reported that the functional hemagglutinin (HA) virus like particle vaccine can be produced in plants within 21 days from identification of sequence for pandemic influenza [15]. The Fraunhofer Centre for Molecular Biotechnology also reported that it takes just over a month to yield purified HA antigens [16]. These vaccines have shown to be highly immunogenic in preclinical animal model, which showed protection against lethal virus challenge, and in human volunteers. Another advantage is probably lower expense for production and easier routines to get bulk stock proteins: 10 to 50 times lower than products derived from Escherichia coli and 140 times lower as compared to production of baculovirus-based insect cells [17]. In addition, plant expression system is safer than conventional expression platform because plants do not contain animal and human pathogens.

Despite of these advantages of plant expression system, only a few of vaccine candidates are under clinical trials and commercial human vaccines are not available due to low level of expression, relatively weak efficacy, and comparatively shallow knowledge on the characteristics of plant-made antigen and production system. It is a challenge to select target antigens carefully and proper plants for high production because the expression levels of the antigen depend on the particular target and specific host plant. An antigen may be highly compatible with one host plant, but not with others [18]. Lack of the consistency of transgene expression in different batches and individual plant within same batch is also a barrier for the application of the plant-based vaccine as an expected oral vaccine. Because of the antigen expression variability, evaluation of the vaccine doses required by individuals is quite challenging.

Glycosylation for the protein folding usually generates different surface affinity of the proteins. Plant specific glycosylation pathway consisting of $\mathrm{N}$-glycan (core $\beta-(1,2)$ xylose and core $\alpha-(1,3))$ fucose moieties is another major challenge for substituting the plant-derived vaccine as an alternative bioreactors of mammalian cell culture due to allergic reactions [19]. However, this challenge has been overcome by either altering the pathway like targeting the antigen production in endoplasmic reticulum where high-Man-type N-glycans are produced or knocking out the $\alpha-(1,3)$ fucose and $\beta-(1,2)$ xylose [20]. In other perspective, it could be seen as an advantage in that chances to alternate the folding formation of ex- 
pressed proteins and binding capacity of the surface antigens. This property may generate more candidates for better vaccination efficacy or larger possibility to find working antigens for the diseases which are difficult for vaccine development such as acquired immune deficiency syndrome. It is notable that different plant polysaccharides are evaluated as adjuvants [21]. However, this issue should be addressed in the future.

Plant factory system was recognized as alternative resources for biopharmaceutical materials and vaccine candidates for a while. Now, techniques to exploit the advantages of plant factory for antigen production such as controlling glycosylation pattern is already established, and more valuable expansion using plants for vaccine development will be suggested and confirmed near future. Not only productivity or edibility, but also the characters to generate more diverse antigens which may not be produced by the microorganisms or mammalian cells should be real paws to consider the plant factory systems. The antigen production by plant factory could be a part of main vaccine development platform as well as alternative approaches. When plant factory is combined with gene-editing technologies, it can give us huge chances for many unmet and needed vaccine developments.

\section{ORCID}

Byoung-Shik Shim https://orcid.org/0000-0001-8627-7008

Kee-Jong Hong https://orcid.org/0000-0003-2054-7014

Puna Maya Maharjan https://orcid.org/0000-0001-9241-0100

Sunghwa Choe https://orcid.org/0000-0001-5541-484X

\section{References}

1. Landry N, Pillet S, Favre D, et al. Influenza virus-like particle vaccines made in Nicotiana benthamiana elicit durable, poly-functional and cross-reactive $\mathrm{T}$ cell responses to influenza HA antigens. Clin Immunol 2014;154:164-77.

2. Hiatt A, Cafferkey R, Bowdish K. Production of antibodies in transgenic plants. Nature 1989;342:76-8.

3. Takeyama N, Kiyono H, Yuki Y. Plant-based vaccines for animals and humans: recent advances in technology and clinical trials. Ther Adv Vaccines 2015;3:139-54.

4. Zhang H, Huang RY, Jalili PR, et al. Improved mass spectrometric characterization of protein glycosylation reveals unusual glycosylation of maize-derived bovine trypsin. Anal Chem 2010;82:10095-101.
5. Arntzen C. Plant-made pharmaceuticals: from 'Edible Vaccines' to Ebola therapeutics. Plant Biotechnol J 2015;13: 1013-6.

6. Chichester JA, Jones RM, Green BJ, et al. Safety and immunogenicity of a plant-produced recombinant hemagglutinin-based influenza vaccine (HAI-05) derived from A/Indonesia/05/2005 (H5N1) influenza virus: a phase 1 randomized, double-blind, placebo-controlled, dose-escalation study in healthy adults. Viruses 2012;4:3227-44.

7. Landry N, Ward BJ, Trepanier S, et al. Preclinical and clinical development of plant-made virus-like particle vaccine against avian H5N1 influenza. PLoS One 2010;5:e15559.

8. Cummings JF, Guerrero ML, Moon JE, et al. Safety and immunogenicity of a plant-produced recombinant monomer hemagglutinin-based influenza vaccine derived from influenza A (H1N1)pdm09 virus: a phase 1 dose-escalation study in healthy adults. Vaccine 2014;32:2251-9.

9. Tacket CO, Mason HS, Losonsky G, Estes MK, Levine MM, Arntzen CJ. Human immune responses to a novel norwalk virus vaccine delivered in transgenic potatoes. J Infect Dis 2000;182:302-5.

10. Kapusta J, Modelska A, Figlerowicz M, et al. A plant-derived edible vaccine against hepatitis B virus. FASEB J 1999; 13:1796-9.

11. Thanavala Y, Mahoney M, Pal S, et al. Immunogenicity in humans of an edible vaccine for hepatitis B. Proc Natl Acad Sci U S A 2005;102:3378-82.

12. Yusibov V, Hooper DC, Spitsin SV, et al. Expression in plants and immunogenicity of plant virus-based experimental rabies vaccine. Vaccine 2002;20:3155-64.

13. Vermij P, Waltz E. USDA approves the first plant-based vaccine. Nat Biotechnol 2006;24:233-4.

14. Margolin E, Chapman R, Williamson AL, Rybicki EP, Meyers AE. Production of complex viral glycoproteins in plants as vaccine immunogens. Plant Biotechnol J 2018 Jun 11 [Epub]. https://doi.org/10.1111/pbi.12963.

15. D'Aoust MA, Couture MM, Charland N, et al. The production of hemagglutinin-based virus-like particles in plants: a rapid, efficient and safe response to pandemic influenza. Plant Biotechnol J 2010;8:607-19.

16. Shoji Y, Farrance CE, Bautista J, et al. A plant-based system for rapid production of influenza vaccine antigens. Influenza Other Respir Viruses 2012;6:204-10.

17. Rosales-Mendoza S, Nieto-Gomez R, Angulo C. A perspective on the development of plant-made vaccines in the fight against Ebola virus. Front Immunol 2017;8:252. 
18. Streatfield SJ. Plant-based vaccines for animal health. Rev Sci Tech 2005;24:189-99.

19. Bardor M, Faveeuw C, Fitchette AC, et al. Immunoreactivity in mammals of two typical plant glyco-epitopes, core alpha(1,3)-fucose and core xylose. Glycobiology 2003;13: 427-34.

20. Strasser R, Stadlmann J, Schahs M, et al. Generation of glyco-engineered Nicotiana benthamiana for the production of monoclonal antibodies with a homogeneous human-like N-glycan structure. Plant Biotechnol J 2008;6: 392-402.

21. Rosales-Mendoza S, Salazar-Gonzalez JA, Decker EL, Reski R. Implications of plant glycans in the development of innovative vaccines. Expert Rev Vaccines 2016;15:915-25. 